\title{
La última reforma de las NIIF y sus efectos en los estados financieros
}

\author{
JosÉ MORALES-DíAZ \\ Instituto de Estudios Bursátiles (IEB), Calle Alfonso XI, 6, 28014 Madrid, España. E-mail: \\ jose.morales@claustro-ieb.es
}

\begin{abstract}
RESUMEN
El IASB ha emitido tres nuevas normas contables que entrarán en vigor durante los ejercicios 2018 y 2019: la NIIF 9 (Instrumentos Financieros), la NIIF 15 (Ingresos de Contratos con Clientes) y la NIIF 16 (Arrendamientos). La NIIF 9 sustituye a la NIC 39 y podrá tener gran impacto en aspectos como la clasificación de activos financieros en categorías (es posible que algunos activos financieros dejen de valorarse a coste amortizado), las provisiones por riesgo de crédito (que, en general se incrementarán) o las modificaciones de deudas (lo cual puede conllevar cambios en los actuales costes financieros reconocidos). La NIIF 15 (que sustituye a la NIC 18 y a la NIC 11) introduce un nuevo modelo de reconocimiento de ingresos basado en las obligaciones de desempeño. Puede impactar, sobre todo, en empresas con proyectos a largo plazo o con potenciales productos y servicios combinados. La NIIF 16 sustituye a la NIC 17 e introduce un nuevo modelo de contabilidad para los arrendatarios que conllevará capitalizar (reconocer en balance) la mayoría de los actuales arrendamientos operativos, por lo que aflorarán nuevos activos y pasivos y cambiarán magnitudes como el EBITDA o el ROA. Los sectores más afectados serán aquellos con mayor volumen de arrendamientos operativos (retail, hoteles, compañías aéreas, etc.).
\end{abstract}

Palabras clave: NIIF 9, NIIF 15, NIIF 16, IASB, FASB.

\section{The Last IFRS Reform and its Effect on Financial Statements}

\begin{abstract}
The IASB has issued three new accounting standards that will be effective during 2018 and 2019: IFRS 9 (Financial Instruments), IFRS 15 (Revenue from Contracts with Customers) and IFRS 16 (Leases). IFRS 9 replaces IAS 39 and may have a large impact on aspects such as the classification of financial assets into categories (it is possible that some financial assets will be no longer measured at amortized cost), impairment provisions (which, in general, will increase) and debts modifications (which may lead to changes in current recognized financial costs). IFRS 15 (which replaces IAS 18 and IAS 11) introduces a new revenue recognition model based on performance obligations. It may impact companies with long-term projects or with potential combined products and services. IFRS 16 replaces IAS 17 and introduces a new accounting model for lessees that will entail capitalizing (recognizing on the balance sheet) the majority of current operating leases, so new assets and liabilities will arise and metrics such as EBITDA and ROA will change. The most affected sectors will be those with the highest volume of operating leases (retail, hotels, airlines, etc.).
\end{abstract}

Keywords: IFRS 9, IFRS 15, IFRS 16, IASB, FASB.

Clasificación JEL: M41, G12

Artículo disponible en versión electrónica en la página www.revista-eea.net, ref. ə-36206 


\section{INTRODUCCIÓN}

En el ámbito de las Normas Internacionales de Información Financiera (NIIF) emitidas por el International Accounting Standards Board (IASB), tres nuevas normas entrarán en vigor durante los ejercicios 2018 y 2019 (todas ellas con gran impacto potencial en los estados financieros de las empresas): la NIIF 9, la NIIF 15 y la NIIF 16.

La NIIF 9 y la NIIF 15 son de aplicación obligatoria para los ejercicios que comiencen a partir de 1 de enero de 2018 y la NIIF 16 es de aplicación obligatoria para los ejercicios que comiencen a partir de 1 de enero de 2019. Para una empresa cuyo cierre de ejercicio anual sea el 31 de diciembre, la NIIF 9 y la NIIF 15 ya son aplicables a la fecha de publicación del presente artículo y la NIIF 16 entrará en vigor en unos meses.

Cabe destacar que las tres normas han sido aprobadas por la Unión Europea para su adopción por parte de las empresas cotizadas europeas en sus estados financieros consolidados (ver Reglamentos de la Comisión 2016/2067 para la NIIF 9, 2016/1905 para la NIIF 15 y 2017/1986 para la NIIF 16) ${ }^{1}$. En los tres casos han sido aprobadas plenamente (sin carve out $t^{2}$ ) y con la misma fecha de primera aplicación que las NIIF “puras”.

Se podría argumentar que una característica común a las tres normas es un notable incremento en la aplicación de juicios de valor y en las estimaciones. Una vez implementadas, se deberán aplicar juicios de valor subjetivos a un mayor número de aspectos (por ejemplo la identificación de obligaciones de desempeño bajo NIIF 15) y se deberán llevar a cabo un mayor número de estimaciones contables (desde la estimación de la probabilidad de quiebra bajo NIIF 9 hasta la estimación del plazo de arrendamiento bajo NIIF 16).

La NIIF 9 ("Instrumentos Financieros") regula la contabilidad de los instrumentos financieros y viene a sustituir a la $\mathrm{NIC}^{3} 39$. Modifica en gran

\footnotetext{
${ }^{1}$ Según el Reglamento (CE) No 1606/2002 del Parlamento Europeo y del Consejo (de 19 de julio de 2002) todas las empresas europeas con valores admitidos a cotización en mercados regulados de la UE deben preparar sus cuentas anuales consolidadas siguiendo las NIIF adoptadas por la UE.

${ }^{2}$ Recordemos que, cuando en el año 2004 la UE aprobó la NIC 39 (la norma predecesora de la NIIF 9) dos partes de la norma no se traspusieron en el Reglamento correspondiente (hubo dos carve out): la opción de valor razonable plena (full fair value option) y varias restricciones relacionadas con la cobertura de carteras (macrocoberturas). La opción de valor razonable plena se reformó por parte del IASB y este carve out desapareció, pero el segundo ha seguido vigente hasta la fecha, de tal forma que bajo NIC 39-UE se permite aplicar el modelo de macrocoberturas en situaciones en las que bajo NIC 39 "pura” no se permite. Ver http://europa.eu/rapid/press-release_MEMO-04265_en.htm?locale=en.

${ }^{3}$ NIC: Norma Internacional de Contabilidad. En el año 2001 el IASB sustituyó a su predecesor el IASC (International Accounting Standards Committee). Las normas emitidas por el IASC se denominaban Normas Internacionales de Contabilidad (NIC), las nuevas normas que emite el
} 
medida aspectos como la clasificación de activos financieros en categorías o las provisiones por riesgo de crédito. De hecho, debido a este último punto, su implementación está teniendo un gran impacto en los estados financieros de las entidades de crédito (incrementando significativamente su nivel de provisiones) ${ }^{4}$.

Hay un aspecto de la NIIF 9 (que no es una modificación de la norma sino más bien un cambio de interpretación) que conllevará un importante ajuste en el cálculo de los gastos financieros de las empresas de todo tipo de sectores: el tratamiento contable de las reestructuraciones de deudas. Hasta tal punto es significativo el ajuste que el diario Expansión tituló recientemente una noticia en los siguiente términos: “Telefónica, Iberdrola y Repsol afrontan ajustes millonarios en sus costes en 2018” (ver Expansión, 2018).

Por su parte, la NIIF 15 ("Ingresos Ordinarios Procedentes de Contratos con Clientes”) regula el reconocimiento de ingresos de contratos con clientes, y sustituye a la NIC 18 y a la NIC 11 . Dicho reconocimiento de ingresos pasa a basarse en el cumplimiento de las denominadas "obligaciones de desempeño" y se estructura en cinco pasos o etapas. La NIIF 15 cambiará el reconocimiento de ingresos en sectores como construcción, telecomunicaciones, farmacéutico y, en general, cualquier sector con potenciales productos y servicios combinados o con contratos a ejecutar durante un período de tiempo.

La NIIF 16 (“Arrendamientos”) regula la contabilidad de los contratos de arrendamiento (tanto para arrendadores como para arrendatarios) y sustituye a la NIC 17. El mayor cambio que introduce la NIIF 16 se centra en el modelo contable a aplicar por parte de los arrendatarios. Anteriormente, los arrendamientos debían clasificar los arrendamientos como operativos o como financieros. Bajo NIIF 16 desaparece esta distinción para los arrendatarios y a todos los arrendamientos bajo el alcance de la norma (con alguna excepción voluntaria) se les aplica el denominado modelo de capitalización, que conlleva reconocer el valor actual de las cuotas a pagar como una deuda (en el pasivo) y el derecho de uso del bien en el activo. En otras palabras, los antiguos arrendamientos operativos "subirán" a balance incrementando el nivel de activos y pasivos e impactando en numerosos ratios (desde EBITDA hasta $\mathrm{ROA}^{5}$ ).

\footnotetext{
IASB se denominan Normas Internacionales de Información Financiera (NIIF). Aún existe varias NIC vigentes. Con relación a las interpretaciones, las que emitió el IASC se denominaban Standing Interpretation Committee (SIC) y las emitidas por el IASB se denominan Comité de Interpretación de las NIIF (CINIIF). Aún existen varias SIC vigentes.

${ }^{4}$ Ver resultados de la encuesta de EY a 29 bancos internacionales: http://www.ey.com/Publication/ vwLUAssets/ey-ifrs-9-impairment-banking-survey-new/\$FILE/ey-ifrs-9-impairment-bankingsurvey.pdf

${ }^{5}$ El EBITDA (Earnings Before Interest, Taxes, Depreciation, and Amortization) generalmente incrementará debido a que el gasto por arrendamiento (que se incluye dentro del EBITDA) se transformará en gasto por amortización y gasto financiero (ambos fuera del EBITDA). El ROA (Return on Assets) generalmente disminuirá debido al incremento en el volumen de activos.
} 
La NIIF 16 tendrá una mayor incidencia en sectores que actualmente tienen un gran volumen de arrendamientos operativos como retail (arrendamiento de locales comerciales), compañías aéreas (arrendamiento de aviones), hoteles (arrendamiento de inmuebles), etc.

Cabe destacar que la reforma de las normas contables que ha conllevado la emisión de las NIIF 9, 15 y 16 se ha realizado en gran parte de forma conjunta entre el IASB y el FASB ${ }^{6}$. Las normas equivalentes emitidas por el FASB son similares pero con diferencias que pueden ser importantes en varias áreas.

La norma equivalente a la NIIF 15 es el $\mathrm{ASC}^{7}$ Topic 606, teniendo ambas normas una gran convergencia. La norma de arrendamientos (ASC Topic 842) incluye un modelo similar a la NIIF 16 (que también conlleva la capitalización de los antiguos arrendamientos operativos) pero con diferencias significativas. La regulación incluida en la NIIF 9 está distribuida por varias normas que incluyen requerimientos que a veces son significativamente distintos.

En los siguientes apartados analizaremos las razones que han llevado al IASB y al FASB a llevar a cabo esta reforma de las normas contables y desarrollaremos los cambios más importantes que conllevará la adopción de cada una de las tres normas. El apartado 2 lo dedicaremos a la NIIF 9, el apartado 3 a la NIIF 15 y el apartado 4 a la NIIF 16. Finalmente, en el apartado 5 incluimos una conclusión final.

\section{LA NUEVA NORMA DE INSTRUMENTOS FINANCIEROS (NIIF 9)}

\subsection{Reforma de la contabilidad de instrumentos financieros}

El IASB y el FASB (conjuntamente "los organismos") llevan varios años trabajando conjuntamente en la armonización de sus normas contables (aunque, tal y como hemos destacado anteriormente, en las últimas normas emitidas no se ha conseguido una plena convergencia). En este contexto, en septiembre de 2002 ambos organismos firmaron el acuerdo denominado "Norwalk Agreement" en el que se comprometían a hacer sus normas compatibles tan pronto como fuera posible, y a coordinar sus futuros programas de trabajo para asegurar que una vez conseguido lo anterior, se mantenga la compatibilidad.

En sus reuniones en abril y octubre de 2005, reafirmaron el compromiso de convergencia entre las NIIF emitidas por el IASB y los US GAAP ${ }^{8}$ emitidos por

\footnotetext{
${ }^{6}$ FASB: Financial Accounting Standards Board, organismo emisor de las normas contables generalmente aceptadas en los Estados Unidos (USGAAP).

${ }^{7}$ ASC: Accounting Standard Codification.

${ }^{8}$ Normas de contabilidad generalmente aceptadas en EEUU (United States Generally Accepted Accounting Principles).
} 
el FASB. En esas mismas reuniones, trataron el tema del futuro de la contabilidad de instrumentos financieros y establecieron tres objetivos a largo plazo con el objetivo de mejorar y simplificar la normativa actual:

1) Requerir que todos los instrumentos financieros se valoren a valor razonable con cambios en la cuenta de resultados.

2) Simplificar o eliminar la necesidad de contabilidad especial de coberturas.

3) Desarrollar nuevas normas para la baja de instrumentos financieros.

Los organismos, en la "Hoja de ruta para la convergencia entre los principios contables NIIF y los principios americanos" (A Roadmap for Convergence between IFRSs and US GAAP - 2006 to 2008, febrero $2006^{9}$ ) reiteraron su compromiso de convergencia. Una de las metas anunciadas para 2008 se tendría que materializar en la publicación de uno o más documentos relacionados con la contabilidad de instrumentos financieros.

Siguiendo este objetivo, en marzo de 2008, ambos organismos emitieron el documento Discussion Paper. Reducing Complexity in Reporting Financial Instruments ${ }^{10}$ (IASB, 2008), en el que desarrollaban cuales eran las mayores causas de la complejidad en la contabilidad de instrumentos financieros y proponían posibles medidas a medio plazo para mejorar la contabilidad de los instrumentos financieros y reducir su complejidad ( $\mathrm{y}$ a la vez avanzar hacia el objetivo marcado a largo plazo).

Para los organismos, la mayor fuente de complejidad en el modelo de contabilidad de instrumentos financieros incluido en la NIC 39, vendría dada por el hecho de que convivan varios métodos de valoración para las distintas categorías de instrumentos financieros (esto es, la NIC 39 incluye un modelo mixto de valoración). De hecho, en la página 14 del documento Discussion Paper. Reducing complexity in reporting financial instruments, el IASB menciona hasta 24 métodos de valoración (o sus variantes) que bajo NIC 39 se aplican a instrumentos financieros u otros elementos en balance.

Existían instrumentos financieros que se valoran a valor razonable con cambios en la cuenta de resultados (como, por ejemplo, los derivados o los instrumentos de negociación); instrumentos que se valoran a coste amortizado (como los instrumentos de deuda designados como "a mantener hasta el vencimiento" o los "préstamos y cuentas a cobrar") o incluso instrumentos que se valoran a valor razonable con cambios en patrimonio neto (como los clasificados como "disponibles para la venta”). Además, puede que un mismo instrumento cambie su método de valoración a lo largo de su vida. Por ejemplo, un instrumento valorado a coste amortizado que se designa en una cobertura de valor

\footnotetext{
${ }^{9}$ Ver: https://www.ifrs.com/updates/fasb/memorandum_0911.html.

${ }^{10}$ En realidad fue un documento inicialmente preparado y emitido por el por el IASB y posteriormente también emitido por el FASB para recabar opiniones al respecto.
} 
razonable (a partir de ese momento, los cambios en el valor razonable por la parte del riesgo cubierto pasarían a reconocerse contra resultados).

Con un modelo de este tipo, puede darse el caso de que dos instrumentos similares se valoren de forma diferente por la misma entidad (por ejemplo, porque uno se designe como de negociación y otro no) o por distintas entidades, lo que a veces dificulta la comparabilidad de estados financieros entre entidades o en el tiempo para la misma entidad. Otros problemas que suelen surgir cuando conviven varios métodos de valoración son:

- Que los criterios para determinar qué instrumentos deben o pueden ser valorados de una determinada forma pueden ser complejos y difíciles de aplicar.

- Puede haber instrumentos para los que no haya unos requerimientos claros.

- Consumo de recursos para los emisores de los estados financieros y sus auditores.

La posible solución para muchos de los problemas actuales pasaba, según el IASB y el FASB, por reconocer todos los instrumentos financieros con un mismo método. Y, para ellos, el único método apropiado para valorar todos los instrumentos financieros era el valor razonable, reconociendo los cambios en la cuenta de resultados.

En este sentido, si se utilizara un único método de valoración para todos los instrumentos financieros, la información financiera sería más fácil de comprender y se facilitarían las comparaciones entre entidades y entre periodos. También se eliminaría gran parte de la complejidad de la normativa contable de instrumentos financieros, debido a que:

- Se eliminarían las reglas que regulan la distinción entre las categorías de instrumentos financieros.

- Se eliminarían las reglas referidas a traspasos entre categorías de instrumentos financieros.

- Se eliminarían las reglas referidas a la identificación y cuantificación del deterioro de valor. Al reconocerse todos los instrumentos a valor razonable contra resultados, el deterioro está implícito en la propia valoración.

- Se reduciría, para muchas transacciones, la necesidad de contabilidad de coberturas.

- Se eliminarían las reglas referidas a la separación de los derivados implícitos en instrumentos financieros.

En el documento Discussion Paper. Reducing complexity in reporting financial instruments, se plantean tres posibles pasos intermedios para ir avanzado 
hacia el objetivo marcado a largo plazo (que todos los instrumentos financieros se reconozcan a valor razonable con cambios en la cuenta de pérdidas y ganancias):

- Cambiar la regulación referida a los métodos de valoración (por ejemplo, reduciendo el número de categorías de instrumentos financieros).

- Reemplazar la regulación de la NIC 39 por un principio general de valoración a valor razonable y algunas opciones excepcionales a dicho principio.

- Simplificar la contabilidad de coberturas.

Según el documento, cada uno de estos enfoques puede considerarse por separado, e incluso pueden considerarse combinaciones de ellos.

Posteriormente, debido en parte al comienzo de la crisis y en parte a las respuestas recibidas al documento y a determinadas presiones, el IASB y el FASB decidieron continuar con un modelo mixto de valoración pero intentando simplificarlo (lo que podría encuadrarse en el primero y el tercero de los pasos intermedios anteriores).

Tal y como señala EY (2012, Capítulo 30, apartado 3), "hasta el comienzo de la crisis, el IASB y el FASB continuaron reiterando su objetivo a largo plazo de requerir que todos los instrumentos financieros se valoren a valor razonable reconociendo los resultados realizados y no realizados en el período en el que ocurran. No obstante, mientras que el IASB está actualmente embarcándose en su proyecto de cambio más importante en esta área, sus últimos requerimientos y propuestas se han desarrollado bajo una presión política significativa y mantienen un modelo mixto de valoración, aunque algo más simple que el de la NIC 39.

El objetivo a largo plazo de los emisores de normas [el IASB y el FASB] de valorar todos los instrumentos financieros a valor razonable siempre ha sido controvertido y ha encontrado una resistencia considerable incluso antes de la crisis. Esto último [la crisis] solamente ha aumentado la oposición de algunas personas. Por tanto, el propósito del IASB de evolucionar hacia un modelo de full fair value parece que se ha frenado significativamente".

La crisis conllevó una fuerte caída de los valores de las inversiones, un incremento de la morosidad y una gran disminución de la liquidez en determinados mercados de deuda. En el caso de instrumentos a valor razonable con cambios en la cuenta de resultados, las disminuciones de valor se reflejaron en la cuenta de resultados. En el caso de instrumentos clasificados como disponibles para la venta, dichas disminuciones se reflejaron en patrimonio siempre que no se tratara de "deterioros". En el caso de los préstamos a coste amortizado, el reconocimiento del deterioro siguió el modelo de "pérdida incurrida” que, generalmente, retrasa la contabilización de la pérdida.

En octubre de 2007, los ministros de finanzas del G7 y los gobernadores de 
los bancos centrales, pidieron al FSF (Financial Stability Forum) que llevara a cabo un análisis de las causas y debilidades que provocaron el inicio de la crisis sub-prime. En abril de 2008 el FSF emitió un informe denominado Enhancing Market and Institutional Resilience ${ }^{11}$. Entre otras cosas, este informe establecía que:

- El IASB debería mejorar el tratamiento contable y la información a revelar con relación a los vehículos fuera de balance, y debería trabajar con otros emisores de normas para conseguir la convergencia internacional.

- El IASB debería mejorar sus normas para incluir más desgloses acerca de las valoraciones, metodologías e incertidumbres asociadas a las valoraciones.

- El IASB debería mejorar su guía con respecto a la obtención del valor razonable en mercados que han dejado de ser activos y, para este fin, debería crear un panel de expertos (Expert Advisory Panel).

Por otro lado, en las reuniones del G20 en Washington (15/11/2008) y en Londres (02/04/2009) se aprobaron varias medidas relacionadas con la información financiera-contable. Concretamente, se acordó que los emisores de normas tendrían que llevar a cabo acciones a partir de 2009 para:

- Reducir la complejidad de las normas contables de instrumentos financieros.

- Reforzar el reconocimiento de provisiones de préstamos incorporando una gama más amplia de información crediticia.

- Mejorar las normas contables en el ámbito de provisiones, exposiciones fuera de balance e incertidumbre en la valoración.

- Alcanzar una mayor claridad y consistencia en la aplicación de las normas de valoración en el ámbito internaciones, trabajando con los supervisores.

- Progresar hacia un único cuerpo de normas contables globales de alta calidad.

- Dentro del marco de emisión independiente de normas contables, mejorar la involucración de las partes interesadas (incluyendo reguladores y mercados) en el IASB.

El IASB y el FASB anunciaron la creación en 2008 del FCAG ${ }^{12}$ (junto a reguladores, preparadores, auditores, etc.) para asegurar que las reformas contables que debían llevarse a cabo a raíz de la crisis se hicieran de forma internacional y coordinada. El FCAG emitió en julio de 2009 un documento ${ }^{13}$

${ }^{11}$ Disponible en: http://www.fsb.org/wp-content/uploads/r_0804.pdf?page_moved=1

${ }^{12}$ FCAG: Financial Crisis Advisory Group.

13 Disponible en: http://www.ifrs.org/-/media/feature/groups/consultative-groups/fcag/report-ofthe-fcag.pdf 
con relación a los aspectos contables que necesitaban una atención más urgente por parte del IASB y el FASB (junto con otros aspectos más a largo plazo).

Por otro lado, los organismos mantuvieron tres reuniones (el 14/11/2008 en Londres, el 25/11/2008 en Norwalk y el 03/12/2008 en Tokio). El objetivo fue recabar información de usuarios de los estados financieros, empresas, reguladores, etc. para identificar los aspectos contables que necesitaban una atención más inmediata y así mejorar los estados financieros emitidos y la confianza de los mercados financieros.

Los comentarios generales que el IASB y el FASB recabaron remarcaron la importancia de trabajar en la convergencia de las normas del FASB y del IASB y de permitir un período de comentarios suficientemente amplio antes de llevar a cabo cualquier reforma contable.

Igualmente, los participantes en las reuniones destacaron las siguientes áreas importantes de la contabilidad de instrumentos financieros: deterioro de valor, opción de valor razonable, valoración a valor razonable, conflictos entre normas, clasificación de las inversiones en CDOs (Collateralized Debt Obligations).

Considerando todo lo anterior, el IASB (al igual que el FASB con relación a su normativa) fue llevando a cabo reformas de la NIC 39 exigidas en gran parte por la situación de crisis financiera (por ejemplo, permitir reclasificar instrumentos financieros fuera de las categorías de valor razonable ${ }^{14}$ ). Además:

- Con relación a los vehículos fuera de balance, en mayo de 2011 el IASB emitió la NIIF 10 (Estados Financieros Consolidados) (que sustituyó a la NIC 27 y a la SIC 12).

- Con relación a las guías de valor razonable y a los desgloses:

- El Expert Advisory Panel emitió una guía de valor razonable para mercados que han dejado de ser líquidos.

- El mayo de 2011 el IASB publicó la NIIF 13 (de valor razonable), una norma similar al marco conceptual de valor razonable bajo USGAAP.

- Se llevaron a cabo varias reformas de la NIIF 7 y de la NIC 32.

A partir de 2009 y siguiendo también las recomendaciones del $\mathrm{G} 20^{15}$, el IASB y el FASB se embarcaron en el proceso de reforma de la contabilidad de instrumentos financieros. Los objetivos marcados fueron:

- En la parte de clasificación y valoración reducir el número de categorías. De hecho el IASB propuso un primer modelo en el que solamente existían

${ }^{14}$ Reclassification of Financial Assets (Amendments to IAS 39 Financial Instruments: recognition and Measurement and IFRS 7 Financial Instruments: Disclosures). Disponible en: https://www.iasplus.com/en/binary/europe/0810arcproposalannex.pdf

15 Ver recomendaciones del G20 en: https://www.iasplus.com/en/binary/resource/0904g20 communique2.pdf 
dos categorías: valor razonable contra resultados y coste amortizado ${ }^{16}$. No obstante, el modelo para activos financieros posteriormente se hizo más complejo para incorporar la posibilidad de que tanto instrumentos de deuda como instrumentos de capital se valoren a valor razonable con cabios en otro resultado global.

- En la parte de provisiones por riesgo de crédito crear un modelo que suponga el reconocimiento más temprano de las pérdidas por riesgo de crédito. Tal y como señala EY (2018, Capítulo 42 apartado 1.4), “durante la crisis financiera, numerosos comentarios criticaron los requerimientos de la NIC 39 por retrasar de forma innecesaria el reconocimiento de las pérdidas por riesgo de crédito. La NIC 39 utiliza el enfoque denominado pérdida incurrida, en el que el deterioro no se reconoce hasta que hay evidencia objetiva de que ha ocurrido el deterioro".

- En la parte de contabilidad de coberturas simplificar los requerimientos para su aplicación e incrementar la alineación entre las políticas de gestión de riesgos de las entidades y la contabilidad de coberturas.

Para Georgiou y Jack (2011, p.311), las recientes controversias acerca del papel del valor razonable en la crisis financiera que emergió en 2007 y la presentación de un modelo mixto para la NIIF 9 hace a uno plantearse si la idea de valor razonable completo está siendo gradualmente abandonada.

\subsection{La emisión de la NIIF 9}

Tal y como hemos comentado anteriormente, la NIIF 9 entra en vigor de forma obligatoria en el ejercicio 2018 (ver párrafo 7.1.1 de la NIIF 9). La versión final de la norma completa se emitió por parte del IASB en julio de 2014 y la Unión Europea la adoptó en noviembre de 2016.

La norma fue desarrollándose en tres fases con el objetivo de que cuando una fase estuviera finalizada, las empresas pudieran aplicar dicha fase anticipadamente de forma voluntaria (antes de que la norma se finalizara). Esto no fue posible en la Unión Europea debido a que la NIIF 9 no se aprobó hasta que la norma se completó definitivamente.

Las tres fases fueron:

- Fase 1: clasificación y valoración de instrumentos financieros (incluyendo baja de balance de activos y pasivos financieros y derivados implícitos).

- Fase 2: provisiones por riesgo de crédito de activos financieros.

- Fase 3: contabilidad de coberturas.

${ }^{16}$ La primera versión de la Fase 1 de la NIIF 9 emitida en noviembre de 2009 solamente contemplaba estas dos categorías. Como veremos más adelante la NIIF 9 se fue emitiendo por fases. 
La regulación de las coberturas de carteras abiertas ${ }^{17}$ inicialmente formaba parte de la fase 3. No obstante, se desligó de la misma en mayo de 2012. El IASB determinó que, por su complejidad, su finalización llevaría más tiempo del previsto y no permitiría cumplir con los plazos marcados para la NIIF 9.

En este contexto, en abril de 2014 el IASB emitió el Discussion Paper (DP): "Accounting for Dynamic Risk Management: a Portfolio Revaluation Approach to Macro Hedging" ${ }^{18}$ que proponía un nuevo enfoque para la contabilidad de la gestión dinámica del riesgo (Portfolio Revaluation Approach (PRA)), que se basaba en técnicas de gestión del riesgo de los bancos. Este DP estuvo abierto a comentarios hasta el 17 de octubre de 2014. Se espera un nuevo DP para 2019.

Precisamente porque la NIIF 9 no da respuesta a la cobertura de carteras dinámicas, las entidades que aplican la NIIF 9 como reemplazo de la NIC 39 tienen tres posibilidades a elegir en la primera aplicación (en la parte de contabilidad de coberturas):

1) Aplicar la NIIF 9 de forma completa.

2) Aplicar la NIIF 9 pero continuar aplicando el modelo de cobertura de valor razonable de carteras de riesgo de tipo de interés incluido en la NIC 39 (NIC 39 párrafos 81A, 89A, AG114-AG132) (ver NIIF 9 párrafo 6.1.3).

3) Continuar aplicando la parte de contabilidad de coberturas de NIC 39 aunque se adopte la NIIF 9 (ver NIIF 9 párrafo 7.2.21). En otras palabras, aplicar la NIIF 9 completa excepto el Capítulo 6 de la misma, que se sustituye por la parte de coberturas de la NIC 39.

En principio, estas alternativas serán aplicables hasta que finalice el proyecto de macrocoberturas de la NIIF 9.

\subsection{Clasificación y valoración de instrumentos financieros}

En la parte de clasificación y valoración de activos financieros, la NIIF 9 introduce cambios significativos en las categorías y el los criterios de clasificación con relación a la NIC 39.

La Tabla 1 muestra las categorías de activos financieros bajo NIIF 9 (descritas en los párrafos 4.1.1 a 4.1.5 de la norma) y algunos detalles relacionados con las mismas, incluyendo qué tipo de elementos se clasifican en ellas. Cabe destacar que, a diferencia de lo que ocurría en NIC 39, el nombre de cada categoría coincide con el método de valoración posterior. Esto es, en la categoría que se

${ }^{17}$ Cobertura de carteras de elementos que son dinámicas. Esto es, la posición de riesgo cubierta cambia con frecuencia y entran y salen elementos de la cartera.

18 Disponible en: http://www.ifrs.org/-/media/project/dynamic-risk-management/discussion-paper/ published-documents/dp-accounting-for-dynamic-risk-management.pdf 


\section{denomina “coste amortizado" los activos financieros incluidos en la misma se valoran posteriormente ${ }^{19}$ a coste amortizado.}

Tabla 1

Categorías para activos financieros bajo NIIF 9

\begin{tabular}{|c|c|c|c|c|c|}
\hline Categoría & Contenido & Valoración inicial & $\begin{array}{l}\text { Valoración } \\
\text { posterior }\end{array}$ & $\begin{array}{l}\text { Deterioro de } \\
\text { valor }\end{array}$ & Otros detalles \\
\hline $\begin{array}{l}\text { 1) Activos } \\
\text { financieros a } \\
\text { coste amortizado }\end{array}$ & $\begin{array}{l}\text { Activos que cumplen } \\
\text { dos condiciones: } \\
\text { (1) el activo se } \\
\text { gestiona bajo un } \\
\text { modelo que supone } \\
\text { mantener los activos } \\
\text { para recibir los flujos } \\
\text { contractuales; } \\
\text { (2) los flujos de caja } \\
\text { son solamente pagos } \\
\text { de principal e intereses } \\
\text { ("SPPI") }\end{array}$ & $\begin{array}{l}\text { Valor razonable } \\
\text { (valor razonable } \\
\text { contraprestación } \\
\text { + costes } \\
\text { transacción). } \\
\text { Excepción para } \\
\text { cuentas a cobrar } \\
\text { de origen } \\
\text { comercial que no } \\
\text { tengan un } \\
\text { componente } \\
\text { significativo de } \\
\text { financiación (valor } \\
\text { nominal) }\end{array}$ & Coste amortizado & $\begin{array}{l}\text { Pérdida } \\
\text { esperada en } \\
\text { función de } \\
\text { los criterios } \\
\text { de NIIF } 9\end{array}$ & $\begin{array}{l}\text { El deterioro de valor } \\
\text { y las diferencias de } \\
\text { cambio se } \\
\text { reconocen contra la } \\
\text { cuenta de } \\
\text { resultados. No se } \\
\text { separan derivados } \\
\text { implícitos }\end{array}$ \\
\hline $\begin{array}{l}\text { 2) Activos } \\
\text { financieros a } \\
\text { valor razonable } \\
\text { con cambios en } \\
\text { patrimonio neto } \\
\text { (otro resultado } \\
\text { global) - } \\
\text { instrumentos de } \\
\text { deuda }\end{array}$ & $\begin{array}{l}\text { Activos que cumplen } \\
\text { dos condiciones: } \\
\text { (1) el activo se } \\
\text { gestiona bajo un } \\
\text { modelo que supone } \\
\text { tanto mantenerlos para } \\
\text { recibir los flujos } \\
\text { contractuales como } \\
\text { venderlos; } \\
\text { (2) los flujos de caja } \\
\text { son solamente pagos } \\
\text { de principal e intereses } \\
\text { ("SPPI") }\end{array}$ & $\begin{array}{l}\text { Valor razonable } \\
\text { (valor razonable } \\
\text { contraprestación + } \\
\text { costes } \\
\text { transacción). }\end{array}$ & $\begin{array}{l}\text { Valor razonable } \\
\text { con cambios en } \\
\text { patrimonio neto } \\
\text { (otro resultado } \\
\text { global) }\end{array}$ & $\begin{array}{l}\text { Pérdida } \\
\text { esperada en } \\
\text { función de } \\
\text { los criterios } \\
\text { de NIIF } 9\end{array}$ & $\begin{array}{l}\text { El deterioro de valor } \\
\text { y las diferencias de } \\
\text { cambio se } \\
\text { reconocen contra la } \\
\text { cuenta de } \\
\text { resultados. No se } \\
\text { separan derivados } \\
\text { implícitos }\end{array}$ \\
\hline $\begin{array}{l}\text { 3) Activos } \\
\text { financieros a } \\
\text { valor razonable } \\
\text { con cambios en la } \\
\text { cuenta de } \\
\text { resultados }\end{array}$ & $\begin{array}{l}\text { Resto de activos } \\
\text { financieros }\end{array}$ & $\begin{array}{l}\text { Valor razonable } \\
\text { (valor razonable } \\
\text { contraprestación } \\
\text { sin incluir costes } \\
\text { de transacción). }\end{array}$ & $\begin{array}{l}\text { Valor razonable } \\
\text { con cambios en la } \\
\text { cuenta de } \\
\text { pérdidas y } \\
\text { ganancias }\end{array}$ & N/A & $\begin{array}{l}\text { No se separan } \\
\text { derivados implícitos. } \\
\text { No se reconoce } \\
\text { deterioro (está } \\
\text { implícito en el valor } \\
\text { razonable). Las } \\
\text { diferencias de } \\
\text { cambio van } \\
\text { implícitas en el valor } \\
\text { razonable }\end{array}$ \\
\hline $\begin{array}{l}\text { 4) Activos } \\
\text { financieros a } \\
\text { valor razonable } \\
\text { con cambios en } \\
\text { patrimonio neto } \\
\text { (otro resultado } \\
\text { global - ajustes } \\
\text { por cambios de } \\
\text { valor) - } \\
\text { instrumentos de } \\
\text { capital }\end{array}$ & $\begin{array}{l}\text { Instrumentos de capital } \\
\text { (acciones) que no son } \\
\text { de negociación, que se } \\
\text { incluirían en la } \\
\text { categoría anterior y } \\
\text { que la empresa decide } \\
\text { incluir en esta } \\
\text { categoría }\end{array}$ & $\begin{array}{l}\text { Valor razonable } \\
\text { (valor razonable } \\
\text { contraprestación + } \\
\text { costes } \\
\text { transacción). }\end{array}$ & $\begin{array}{l}\text { Valor razonable } \\
\text { con cambios en } \\
\text { patrimonio neto } \\
\text { (otro resultado } \\
\text { global). El cambio } \\
\text { de valor no } \\
\text { revierte a la } \\
\text { cuenta de } \\
\text { pérdidas y } \\
\text { ganancias }\end{array}$ & N/A & $\begin{array}{l}\text { No se separan } \\
\text { derivados implícitos. } \\
\text { No se reconoce } \\
\text { deterioro (está } \\
\text { implícito en el valor } \\
\text { razonable). Las } \\
\text { diferencias de } \\
\text { cambio van } \\
\text { implícitas en el valor } \\
\text { razonable }\end{array}$ \\
\hline
\end{tabular}

${ }^{19}$ Tanto la NIC 39 como la NIIF 9 distinguen entre valoración inicial (el importe porque se valora el instrumento financiero en el momento de su reconocimiento inicial) y valoración posterior (el método de valoración que se aplica a partir del reconocimiento inicial). 
Tabla 1 (continuación)

Categorías para activos financieros bajo NIIF 9

\begin{tabular}{|l|l|l|l|l|l|}
\hline \multicolumn{1}{|c|}{ Categoría } & \multicolumn{1}{|c|}{ Contenido } & Valoración inicial & \multicolumn{1}{c|}{$\begin{array}{c}\text { Valoración } \\
\text { posterior }\end{array}$} & $\begin{array}{l}\text { Deterioro de } \\
\text { valor }\end{array}$ & \multicolumn{1}{c|}{ Otros detalles } \\
\hline $\begin{array}{l}\text { 5) Activos } \\
\text { financieros a } \\
\text { valor razonable } \\
\text { con cambios en la } \\
\text { cuenta de } \\
\text { resultados } \\
\text { (opción de valor } \\
\text { razonable) }\end{array}$ & $\begin{array}{l}\text { Reducción o } \\
\text { eliminación de } \\
\text { asimetrías contables }\end{array}$ & $\begin{array}{l}\text { Valor razonable } \\
\text { (valor razonable } \\
\text { contraprestación } \\
\text { sin incluir costes } \\
\text { de transacción). }\end{array}$ & $\begin{array}{l}\text { Valor razonable } \\
\text { con cambios en la } \\
\text { cuenta de } \\
\text { pérdidas y } \\
\text { ganancias }\end{array}$ & N/A & $\begin{array}{l}\text { No se separan } \\
\text { derivados implícitos. } \\
\text { No se reconoce } \\
\text { deterioro (está } \\
\text { implícito en el valor } \\
\text { razonable). Las } \\
\text { diferencias de } \\
\text { cambio van } \\
\text { implícitas en el valor } \\
\text { razonable }\end{array}$ \\
\hline
\end{tabular}

Fuente: Elaboración propia.

Como puede observarse en la Tabla 1, bajo la NIIF 9 para que un activo financiero pueda valorarse a coste amortizado (la primera categoría incluida en la tabla) dicho activo financiero debe cumplir dos test:

- “Test del modelo de negocio” (párrafo B4.1.1 a B4.1.6 de la NIIF 9): el instrumento se gestiona bajo un modelo de negocio que supone mantenerlo para recibir los flujos contractuales.

- “Test de los flujos contractuales” (párrafo B4.1.7 a B4.1.26 de la NIIF 9): los flujos contractuales son solamente pagos de principal e intereses $\left(\mathrm{SPPI}^{20}\right)$.

En caso de que no se cumpla con alguno de los test anteriores el activo financiero debe valorarse obligatoriamente a valor razonable en balance (ya sea contra resultados o contra patrimonio dependiendo de la categoría). Por tanto, las empresas deben estar atentas, a la hora de adquirir un nuevo activo financiero, al cumplimiento de los test anteriores en caso de que deseen aplicar el método de coste amortizado a una cartera concreta y no tener volatilidades patrimoniales. En numerosas empresas (sobre todo financieras) se están implementando procesos para este propósito.

En la implementación de la NIIF 9 podría existir impacto patrimonial en el caso de activos financieros que actualmente (bajo NIC 39) se valoran a coste amortizado y que bajo NIIF 9 no se podrían mantener a coste amortizado. Algunos casos podrían ser los siguientes:

- Una cartera de cuentas a cobrar de clientes comerciales sobre la que se suelen firmar contratos de factoring para su venta antes el vencimiento (y la venta supone la baja de balance de la cuenta a cobrar). Para dicha cartera es posible que no se cumpla el test del modelo de negocio debido

${ }^{20}$ SPPI: Solely Payments of Principal and Interest. 
a que las cuentas a cobrar no se mantendrían para recibir los flujos contractuales (se venden antes del vencimiento) ${ }^{21}$.

- Un préstamo participativo concedido en el que los intereses a cobrar dependen del resultado o del EBITDA del prestatario. No se cumpliría el test de los flujos contractuales.

En la parte de clasificación y valoración de pasivos financieros la NIIF 9 no introduce cambios en las categorías con respecto a la NIC 39.

Tabla $2^{22}$

Categorías para pasivos financieros bajo NIIF 9

\begin{tabular}{|c|c|c|c|c|}
\hline Categoría & Contenido & Valoración inicial & Valoración posterior & Otros detalles \\
\hline $\begin{array}{l}\text { 1) Pasivos } \\
\text { financieros } \\
\text { mantenidos para } \\
\text { negociar y } \\
\text { "otros pasivos } \\
\text { financieros a } \\
\text { valor razonable } \\
\text { con cambios en } \\
\text { la cuenta de } \\
\text { pérdidas y } \\
\text { ganancias" } \\
\text { (opción de valor } \\
\text { razonable) }\end{array}$ & $\begin{array}{l}\text { Pasivos financieros de } \\
\text { negociación y pasivos } \\
\text { financieros designados } \\
\text { a valor razonable bajo la } \\
\text { opción de valor } \\
\text { razonable (reducción o } \\
\text { eliminación de } \\
\text { asimetrías contables / } \\
\text { grupos de instrumentos } \\
\text { financieros gestionados } \\
\text { y evaluados en base a } \\
\text { su valor razonable) }\end{array}$ & $\begin{array}{l}\text { Valor razonable (sin } \\
\text { incluir costes de } \\
\text { transacción) }\end{array}$ & $\begin{array}{l}\text { Valor razonable (cambios } \\
\text { imputados a la cuenta de } \\
\text { pérdidas y ganancias). En } \\
\text { el caso de "otros pasivos } \\
\text { financieros a valor } \\
\text { razonable con cambios en } \\
\text { la cuenta de pérdidas y } \\
\text { ganancias" la contrapartida } \\
\text { es el patrimonio neto (otro } \\
\text { resultado global) para los } \\
\text { cambios de valor } \\
\text { atribuibles al propio riesgo } \\
\text { de crédito (excepto si esto } \\
\text { crea o aumenta una } \\
\text { asimetría contable). }\end{array}$ & $\begin{array}{l}\text { No se separan } \\
\text { derivados } \\
\text { implícitos. Las } \\
\text { diferencias de } \\
\text { cambio van } \\
\text { implícitas en el } \\
\text { valor razonable }\end{array}$ \\
\hline $\begin{array}{l}\text { 2) Débitos y } \\
\text { partidas a pagar }\end{array}$ & $\begin{array}{l}\text { Resto de pasivos } \\
\text { financieros }\end{array}$ & $\begin{array}{l}\text { Valor razonable } \\
\text { (valor razonable } \\
\text { contraprestación - } \\
\text { costes transacción) }\end{array}$ & Coste amortizado & $\begin{array}{l}\text { Las diferencias de } \\
\text { cambio se } \\
\text { reconocen contra la } \\
\text { cuenta de } \\
\text { resultados. Se } \\
\text { separan derivados } \\
\text { implícitos si son } \\
\text { separables }\end{array}$ \\
\hline
\end{tabular}

Fuente: Elaboración propia.

El principal cambio estaría en los pasivos financieros que se clasifican a valor razonable con cambios en la cuenta de resultados bajo la llamada “opción de valor razonable”. En estos casos, el cambio de valor del pasivo financiero debe dividirse en dos partes (NIIF 9 párrafo 5.7.7.):

- La parte asignable a cambios en el propio riesgo de crédito. Esta parte se reconoce en otro resultado global (patrimonio neto) excepto si crea o

${ }^{21}$ Asumiendo que no se considera que las ventas están cercanas al vencimiento de tal forma que el importe que se obtiene es similar al que se obtendría al recibir los flujos de caja contractuales (ver párrafo B4.1.3B de la NIIF 9).

${ }^{22}$ En esta tabla no se incluyen: pasivos financieros que surgen cuando un activo financiero no puede darse de baja de balance, contratos de garantía financiera, compromisos de concesión de un préstamo a un tipo de interés inferior al de mercado ni la contraprestación contingente reconocida por una adquirente en una combinación de negocios a la que se aplique la NIIF 3. 
incrementa una asimetría contable, en cuyo caso se registraría contra la cuenta de resultados (ver párrafos B5.7.13 a B5.7.20 de la NIIF 9).

- Resto del cambio de valor. Esta parte se reconoce contra la cuenta de resultados.

\subsection{Baja de balance de activos y pasivos financieros}

Las normas de baja de balance de activos financieros no se ven modificadas con la introducción de la NIIF 9 (para un estudio pormenorizado de las mismas ver Morales, 2012).

Las normas de baja de balance de pasivos financieros tampoco se ven modificadas (ver Morales, 2014). No obstante, existe un cambio de interpretación en un aspecto que puede conllevar un gran impacto en numerosas empresas.

Debido a que dicho cambio de interpretación se emitió cuando aún la NIC 39 estaba en vigor ${ }^{23}$, surgió la duda de si el cambio afectaba también a la NIC 39 o si era solamente aplicable a NIIF 9 (siendo esta parte de ambas normas idéntica). Para EY (2017, p.3) "el IASB establece de forma específica que esta aclaración se refiere a la aplicación de la NIIF 9. Por tanto, no parece que esta aclaración debe aplicase bajo NIC 39 (...). Las entidades que no han aplicado esta contabilidad bajo NIC 39 es probable que tengan un cambio de contabilidad en la transición. Como no hay un alivio específico, este cambio debería realizarse de forma retrospectiva”.

El cambio se refiere al caso en el que una empresa, que mantiene una deuda financiera, llega a un acuerdo con su acreedor para modificar sus condiciones ${ }^{24}$. El tratamiento contable de la modificación depende de si la nueva deuda que surge tras la reestructuración tiene o no términos "sustancialmente diferentes" a la deuda original, lo cual se analiza a través del denominado test del $10 \%{ }^{25}$ :

- Si el resultado del test arroja un resultado inferior al $10 \%$ se asume que la deuda no tiene términos "sustancialmente diferentes" (sigue siendo la misma deuda).

- En caso contrario (el resultado del test es superior al 10\%) se asume que la deuda sí tiene términos "sustancialmente diferentes".

La diferencia que introduce la NIIF 9 está en el caso en el que el resultado del test sea inferior al $10 \%$ (la deuda es contablemente la misma):

${ }^{23}$ El cambio de interpretación fue finalmente confirmado por el IASB en el documento "Prepayment Features with Negative Compensation. Amendments to IFRS 9", emitido en octubre de 2017 (párrafos BC4.252 y BC4.253).

${ }^{24}$ Ya sea modificando el propio contrato o reemplazando la deuda por otra nueva con distintas condiciones. En cualquier caso el acreedor no cambiaría. Si el acreedor cambia generalmente la deuda que surge tras la modificación de términos es una nueva deuda sin mayor análisis.

${ }^{25}$ También suele interpretarse que debe llevarse a cabo un test cualitativo además del test del 10\%. 
- Anteriormente (bajo la NIC 39) esto conllevaba simplemente reconocer las comisiones de reestructuración contra el propio pasivo financiero y recalcular el tipo de interés efectivo de la operación.

- En cambio, bajo NIIF 9, la empresa debe reconocer un resultado por la diferencia entre el importe en balance original y el valor actual de los nuevos flujos descontados al tipo de interés efectivo original. Una vez realizado este ajuste las comisiones de reestructuración se reconocen contra el propio pasivo financiero y se recalcula el tipo de interés efectivo de la operación.

En otras palabras, anteriormente un cambio en el tipo de interés se reconocía de forma "prospectiva" debido a que se recalculaba el tipo de interés efectivo. En cambio, con la NIIF 9, se reconoce de forma inmediata en la cuenta de resultados por coherencia con el tratamiento contable de la reestructuración de activos financieros (párrafo 5.4.3 de la NIIF 9). Por ejemplo, si el tipo de interés de la deuda se reduce, anteriormente bajaba el tipo de interés efectivo y bajo NIIF 9 el tipo de interés efectico se mantiene igual (excepto por el efecto de las comisiones) y el "ahorro" financiero se reconoce completo en la fecha de renegociación contra resultados (reconociendo un menor valor de la deuda).

Si una empresa mantiene en la primera aplicación en su balance una deuda reestructurada (que se reestructuró antes de la fecha de primera aplicación) debe ajustar su importe de forma retrospectiva para adecuarlo a la nueva interpretación. Dada la situación actual de los tipos de interés, numerosas empresas han modificado sus deudas en los últimos años con el objetivo de disminuir el tipo de interés. Esto generalmente conllevará en la transición un ajuste positivo contra reservas y un mayor gasto financiero futuro.

\subsection{Provisiones por riesgo de crédito}

Bajo NIC 39, el modelo de provisiones por riesgo de crédito se basaba en el reconocimiento de las "pérdidas incurridas". La entidad no podía reconocerse ninguna pérdida hasta que estuviera "incurrida". Esto es, hasta que se hubiera dado un hecho (loss event) que pudiera conllevar pérdidas futuras. La provisión genérica debía estimarse considerando el principio de IBNR (Incurred But Not Reported).

A NIIF 9 introduce el modelo de las tres etapas basado en la pérdida esperada. Todos los préstamos sobre los que deban calcularse las pérdidas por deterioro deben clasificarse en una de las tres etapas. Los préstamos se incluyen inicialmente en la primera etapa. Si existe un incremento significativo del riesgo de crédito pasan a la etapa 2 y si la pérdida está incurrida pasan a la etapa 3.

Para los préstamos en la etapa 1 se provisionan las perdidas esperadas utilizando la probabilidad de quiebra a un horizonte solamente de un año. En 
cambio para los préstamos en las etapas 2 y 3 se provisionan todas las pérdidas esperadas (utilizando la probabilidad de quiebra hasta el vencimiento del activo financiero).

En general, el cálculo de pérdida esperada seguirá un enfoque similar a Basilea en el caso de entidades de crédito (pero con algunas diferencias como, por ejemplo, el hecho de que en la NIIF 9 la información a utilizar haya que ajustarla con expectativas acerca de las futuras condiciones del mercado, esto es, se trata de una provisión forward looking):

- Pérdida Esperada = EAD x PD x LGD x DF

- Dónde:

- $\mathrm{EAD}=$ Exposure at default, exposición al riesgo en el momento de la quiebra.

- $\mathrm{PD}=$ Probability of default, es decir, probabilidad de quiebra. En el caso de la Etapa 1 solamente se considera para los siguientes 12 meses.

- LGD= Loss Given Default. 1 menos la tasa de recuperación en caso de quiebra.

- $\mathrm{DF}=$ Discount Factor.

En el caso de activos que se adquieran deteriorados (con existencia de evidencia objetiva de deterioro desde el inicio) no se incluyen inicialmente en la etapa 1 ni se reconoce provisión desde el primer día. Se irán reconociendo pérdidas o ganancias a medida que varíen las condiciones iniciales existentes en el riesgo de crédito de la operación. En todo caso, se reconoce la pérdida esperada hasta el vencimiento (NIIF párrafos 9.5.5.13 y 5.5.14).

Por otro lado, la NIIF 9 incluye un modelo simplificado como excepción al modelo de las tres etapas (aplicable, entre otros, a cuentas a cobrar comerciales) ${ }^{26}$. En este caso, no se aplican las etapas y se reconoce toda la pérdida esperada desde el inicio.

A la hora de aplicar este enfoque simplificado, NIIF 9 permite a las entidades utilizar soluciones prácticas (NIIF 9 B5.5.35). Un ejemplo de una solución práctica es el cálculo de las pérdidas crediticias esperadas sobre cuentas por cobrar comerciales utilizando una matriz de provisiones. Las entidades utilizarían su experiencia de pérdidas crediticias histórica para cuentas a cobrar comerciales

${ }^{26}$ El modelo simplificado es aplicable obligatoriamente a cuentas comerciales a cobrar o activos de los contratos que procedan de transacciones que están dentro del alcance de la NIIF 15 y que no contienen un componente financiero significativo. Es aplicable voluntariamente a: las cuentas comerciales a cobrar o activos de contratos que procedan de transacciones bajo el alcance de la NIIF 15 que contienen un componente financiero significativo y las cuentas a cobrar por arrendamientos. 
para estimar las pérdidas crediticias esperadas durante el tiempo de vida del activo sobre los activos financieros.

En la práctica, muchas empresas utilizan matrices de provisión o métodos similares basados en datos históricos para calcular el deterioro de sus carteras de cuentas a cobrar comerciales. Esto sobre todo es de aplicación en el caso de carteras de cuentas a cobrar con múltiples deudores de similares características de riesgo de crédito. Sin embargo, para cumplir con los requisitos de NIIF 9, las empresas deben analizar cómo la información actual y prospectiva ("información forward looking") podría afectar a las tasas de incumplimiento históricas de sus clientes y, consecuentemente, cómo dicha información afectaría a sus expectativas actuales y las estimaciones de la pérdida esperada.

\subsection{Contabilidad de coberturas}

Por la parte de contabilidad de coberturas la NIIF 9 no introduce novedades en el modelo general. Simplemente facilita aplicar contabilidad de coberturas a más coberturas económicas y trata de alinear en mayor medida la gestión de riesgos y la contabilidad de coberturas.

La filosofía general de la contabilidad de coberturas de la NIIF 9 es la misma que la de la NIC 39: la aplicación de un modelo voluntario para evitar asimetrías contables en los casos en los que un instrumento financiero a valor razonable con cambios en la cuenta de resultados (en muchas ocasiones, un derivado) compensa o cubre los cambios en el valor o en los flujos de una operación cuyo reconocimiento en la cuenta de resultados se produce en un momento distinto.

De hecho, los tres modelos de contabilidad de coberturas son los mismos en ambas normas: coberturas de flujos de efectivo, valor razonable e inversiones netas.

La NIIF 9 conllevará simplificaciones en la medición de la efectividad, permitirá designar un mayor número de elementos como instrumento de cobertura y elemento cubierto y mejorará la contabilidad del valor temporal, los puntos forward y los basis de divisa cuando se excluyen de la cobertura.

\section{LA NUEVA NORMA DE RECONOCIMIENTO DE INGRESOS (NIIF 15)}

\subsection{Reforma de la contabilidad de reconocimiento de ingresos}

La reforma de la contabilidad de los ingresos de contratos con clientes se puede decir que comenzó en el año 2002, cuando el IASB incluyó este asunto en su agenda. El 19 de diciembre de 2008 se emitió el primer documento (de forma conjunta por parte del IASB y el FASB): Discussion Paper: Preliminary Views on Revenue Recognition in Contracts with Customers published. En junio 
de 2010 se emitió el primer borrador de norma y en mayo de 2014 se emitió la norma definitiva.

Los objetivos básicos de la reforma de la contabilidad de los ingresos con clientes han sido los siguientes (ver NIIF 15 párrafo IN5):

1) Eliminar inconsistencias y debilidades en la literatura relacionada con el reconocimiento de ingresos. En este sentido, las normas de reconocimiento de ingresos estaban escasamente desarrolladas en aspectos como licencias, contraprestaciones variables, costes de adquisición de contratos, transacciones con varios componentes, etc.

2) Crear un marco más robusto para enfocar los aspectos del reconocimiento de ingresos. Por ejemplo, antes de la NIIF 15 existían dos modelos de reconocimiento de ingresos (venta de bienes y prestación de servicios) sin que hubiera criterios claros para distinguir entre las dos situaciones.

3) Mejorar la comparabilidad del reconocimiento de ingresos entre sectores y entre las empresas dentro de un mismo sector.

4) Reducir la complejidad a la hora de aplicar los requerimientos de reconocimiento de ingresos reduciendo el número de normas e interpretaciones.

5) Dar una información más útil a los usuarios de información financiera incrementando los desgloses en los estados financieros.

Desde que la norma se emitió, los organismos han publicado varias modificaciones a sus normas. Cabe destacar que no llegaron a un acuerdo en todos los cambios realizados, no obstante, han afirmado que esperan que las modificaciones lleven a resultados similares en muchos casos.

La fecha de primera aplicación obligatoria de la NIIF 15 era, originalmente, para ejercicios que comenzaran a partir del 1 de enero de 2017. No obstante, en septiembre de 2015 el IASB retrasó un año dicha fecha para dejar más tiempo a las entidades en el proyecto de implementación ${ }^{27}$. Posteriormente, en abril de 2016 publicó la modificación Clarifications to IFRS 15 Revenue from Contracts with Customers con el objetivo de clarificar algunos aspectos de la implementación relacionados con interpretaciones de la norma (algunos de los cuales fueron previamente analizados por el $\mathrm{TRG}^{28}$ ).

27 En septiembre de 2015 el IASB publicó la modificación Amendment: Effective Date of IFRS 15. El FASB también retrasó la fecha de primera aplicación obligatoria de su norma.

${ }^{28}$ Joint Transition Resource Group for Revenue Recognition. Grupo creado para analizar aspectos relacionados con la implementación de la norma e informar al IASB y al FASB con relación a estos aspectos. 


\subsection{La nueva NIIF 15}

La NIIF 15 incluye un marco conceptual para establecer cuándo debe reconocerse un ingreso relacionado con un contrato con un cliente y por qué importe. La nueva regulación es notablemente más extensa y detallada que la incluida en las normas anteriores y puede provocar cambios en el momento en el que la empresa se reconoce los ingresos (ya sea atrasando o anticipando su reconocimiento) en:

- Sectores en los que suele venderse al cliente varios bienes o servicios "diferenciados" en un mismo contrato.

- Sectores en los que suele entregar un incentivo al cliente (por ejemplo un bien "gratuito") para que firme el contrato.

- Sectores en los que se mantienen contratos a largo plazo con clientes.

El principio básico es que una entidad debe reconocer los ingresos para reflejar la transferencia de los bienes o servicios comprometidos con los clientes por un importe que refleje la contraprestación a la que la entidad espera tener derecho a cambio de dichos bienes o servicios (párrafo 2 de la NIIF 15).

A la hora de reconocer el ingreso deben aplicarse cinco pasos o etapas que están desarrolladas en la propia norma.

Figura 1

Las 5 etapas de la NIIF 15

Etapa 1: identificar el/los contrato/s con el cliente

Etapa 2: identificar las obligaciones de desempeño que se incluyen en el contrato

Etapa 3: determinar el precio de la transacción

Etapa 4: asignar el precio de la transacción a las obligaciones de desempeño

Etapa 5: reconocer el ingreso

Fuente: Elaboración propia. 


\section{Etapa 1: identificar el contrato con el cliente}

Un contrato se define como un acuerdo entre dos o más partes que crea derechos y obligaciones exigibles. Dicho contrato puede ser por escrito, oral, o implícito en las prácticas de negocios con clientes de la entidad (ver párrafo 10 de la NIIF 15).

El contrato debe cumplir con los siguientes requisitos para estar en el alcance de la NIIF 15 (párrafo 9 de la NIIF 15):

- Que las partes del contrato lo hayan aprobado (por escrito, oralmente o de conformidad con otras prácticas comerciales habituales) y se hayan comprometido a satisfacer sus obligaciones respectivas.

- Que la entidad pueda identificar los derechos de cada una de las partes en relación con los bienes o servicios a transferir.

- Que la entidad pueda identificar las condiciones de pago en relación con los bienes o servicios a transferir.

- Que el contrato tenga carácter comercial (es decir, se espera que el riesgo, el calendario o el importe de los flujos de efectivo futuros de la entidad cambien como resultado del contrato).

- Que sea probable que la entidad vaya a cobrar la contraprestación a que tendrá derecho a cambio de los bienes o servicios que se transferirán al cliente; al evaluar si es probable el cobro del importe de la contraprestación, la entidad deberá tomar en consideración únicamente la capacidad y la intención del cliente de pagar ese importe a su vencimiento; el importe de contraprestación al que tendrá derecho la entidad podrá ser inferior al precio indicado en el contrato si la contraprestación es variable, ya que la entidad puede ofrecer al cliente una reducción de precio (ver párrafo 52 de la NIIF 15).

En principio, la "unidad de cuenta" a efectos de la aplicación de la NIIF 15 es el contrato. Esto es, la norma debe aplicarse a cada contrato individual con un cliente $^{29}$. No obstante, la NIIF 15 obliga a combinar contratos que se firman con el mismo cliente (o partes relacionadas) en la misma fecha o en una fecha cercana, siempre que se cumplan las circunstancias incluidas en el párrafo 17 de la NIIF 15.

Por otro lado, en caso de modificación de los términos de un contrato previamente existente, dicha modificación puede tratarse como un nuevo contrato

${ }^{29}$ El párrafo 4 de la NIIF 15 permite, como simplificación práctica, aplicar la norma a una cartera de contratos (u obligaciones de desempeño) con características similares si la entidad espera de forma razonable que los efectos sobre los estados financieros de aplicar la NIIF 15 a la cartera no diferirían de forma significativa de su aplicación a cada contrato individual (u obligación de desempeño) de la cartera. Al contabilizar una cartera, la entidad debe utilizar estimaciones y suposiciones que reflejen el tamaño y la composición de la cartera. 
o como parte del contrato original dependiendo de los criterios especificados en la norma (ver párrafos 20 y 21 de la NIIF 15).

\section{Etapa 2: identificar las obligaciones de desempeño}

La NIIF 15 establece que al inicio del contrato deben analizarse los bienes y servicios que contiene con el objetivo de identificar las denominadas “obligaciones de desempeño”. Según el párrafo 22 de la NIIF 15, una obligación de desempeño es: "un compromiso de transferir al cliente:

a) un bien o servicio (o un grupo de bienes o servicios) diferenciado; o

b) una serie de bienes o servicios diferenciados que sean prácticamente iguales y que se atengan al mismo patrón de transferencia al cliente”.

La identificación de las obligaciones de desempeño es una de las claves de la norma. Si un contrato con un cliente tiene, por ejemplo, dos obligaciones de desempeño, será necesario, como veremos más adelante, asignar una parte del precio a cada una de ellas y analizar de forma independiente, para cada una, en qué momento debe reconocerse el ingreso (que no tiene por qué coincidir). Por ejemplo, imaginemos un contrato a través del cual al cliente se le entrega un bien y, además, se le presta un servicio durante un período de tiempo.

Según el párrafo 27 de la NIIF 15, un bien o servicio comprometido con un cliente está diferenciado (y por tanto representa una obligación de desempeño independiente) si se cumplen, a la vez, los dos criterios siguientes:

a) Capacidad de ser distinto: el cliente puede disfrutar del bien o servicio por sí solo o junto con otros recursos de los que pueda disponer fácilmente (es decir, el bien o servicio puede existir de forma diferenciada).

- Un cliente puede disfrutar de un bien o servicio de acuerdo con el párrafo 27, letra a), si el bien o servicio puede utilizarse, consumirse, venderse por un importe mayor que su valor como desecho o conservarse de cualquier forma que genere beneficios económicos. En el caso de algunos bienes o servicios, un cliente puede tener la posibilidad de disfrutar de uno de ellos por sí solo. En el caso de otros, es posible que el cliente solo pueda disfrutar de un bien o servicio junto con otros recursos fácilmente disponibles. Un recurso fácilmente disponible es un bien o servicio vendido por separado (por la entidad o por otra entidad) o un recurso que el cliente ya haya obtenido de la entidad (incluidos los bienes o servicios que la entidad ya haya transferido al cliente en virtud del contrato) o en el marco de otras transacciones o sucesos. Diversos factores pueden evidenciar la posibilidad para el cliente de disfrutar de un bien o servicio por sí solo o junto con otros recursos fácilmente disponibles. El hecho de que la 
entidad venda con regularidad un bien o servicio por separado representa un ejemplo de tal posibilidad.

b) Distinto en el contexto del contrato: el compromiso de la entidad de transferir el bien o servicio al cliente es identificable por separado de otros compromisos incluidos en el contrato.

- Los siguientes factores sugieren que el compromiso de una entidad de transferir un bien o servicio a un cliente es identificable por separado:

a) La entidad no proporciona un servicio significativo de integración del bien o servicio con otros bienes o servicios prometidos en el contrato dentro de un grupo de bienes o servicios que representan el producto combinado que el cliente ha contratado. En otras palabras, la entidad no está utilizando el bien o servicio como insumo para producir o suministrar el producto combinado especificado por el cliente.

b) El bien o servicio no modifica significativamente ni adapta al cliente otro bien o servicio prometido en el contrato.

c) El bien o servicio no depende en medida considerable de otros bienes o servicios prometidos en el contrato ni está estrechamente interrelacionado con ellos. Por ejemplo, el hecho de que un cliente pueda decidir no comprar el bien o servicio sin que ello afecte de forma significativa a los demás bienes o servicios prometidos en el contrato podría indicar que el bien o servicio no depende en medida considerable de esos otros bienes o servicios prometidos ni está estrechamente interrelacionado con ellos.

Si se determina que un bien o servicio prometido no está diferenciado, la entidad lo debe combinar con otros bienes o servicios comprometidos hasta que identifique un grupo diferenciado de bienes o servicios. En algunos casos, ello puede dar lugar a que la entidad contabilice todos los bienes o servicios prometidos en el contrato como una única obligación de desempeño.

\section{Etapa 3: determinar el precio de la transacción}

El precio de la transacción es el importe de la contraprestación a la que la entidad espera tener derecho a cambio de transferir los bienes o servicios prometidos a un cliente, con exclusión de los importes cobrados por cuenta de terceros (por ejemplo, algunos impuestos sobre las ventas). La contraprestación prometida en un contrato con un cliente puede consistir en importes fijos, en importes variables, o ambos, y no incluye los importes cobrados en nombre de terceros (por ejemplo algunos tipos de impuestos) (ver párrafo 47 de la NIIF 15). 
Algunos aspectos a considerar a la hora de determinar el precio de la transacción son:

- Cómo estimar los pagos variables. La NIIF 15 incluye dos posibles métodos: el valor esperado o el importe más probable (párrafo 53 de la NIIF 15). En cualquier caso, debe considerarse la limitación de las estimaciones de la contraprestación variable incluida en los párrafos 56 a 58 de la NIIF 15.

- El valor temporal del dinero, esto es, la existencia de una financiación implícita en el contrato (ver párrafos 60 a 65 de la NIIF 15).

- Contraprestaciones distintas del efectivo (ver párrafos 66 a 69 de la NIIF 15).

- Contraprestaciones a pagar al cliente (ver párrafos 70 a 72 de la NIIF 15).

\section{Etapa 4: asignar el precio entre las obligaciones de desempeño.}

El precio de la transacción generalmente se asigna a las obligaciones de desempeño basándose en el precio relativo de venta independiente (o individual) de cada una de dichas obligaciones de desempeño.

Dicho precio de venta independiente es el precio al cual una entidad vendería un bien o servicio de forma separada a un cliente, en circunstancias similares y a clientes parecidos:

- Si existen precios directamente observables para una obligación de desempeño, esta sería la mejor evidencia de su precio de venta independiente. Este precio puede ser distinto al precio del contrato o al precio de catálogo (párrafo 77 de la NIIF 15).

- En caso contrario, debe considerarse toda la información razonablemente disponible a la hora es estimar el precio de venta independiente (párrafo 78 de la NIIF 15).

\section{Etapa 5: reconocer el ingreso.}

Según el párrafo 31 de la NIIF 15, la entidad reconocerá los ingresos cuando (o a medida que) satisfaga una obligación de ejecución mediante la transferencia de un bien o servicio prometido (es decir, un activo) a un cliente. Un activo se transfiere cuando (o a medida que) el cliente obtiene el control de ese activo.

Básicamente el ingreso debe reconocerse en un momento concreto o a lo largo de un período de tiempo dependiendo de cómo se satisface la obligación de desempeño.

Según el párrafo 35 de la NIIF 15, la entidad transfiere el control de un bien o servicio a lo largo del tiempo y, por ende, satisface una obligación de 
ejecución y reconoce los ingresos ordinarios a lo largo del tiempo, si se cumple uno de los siguientes criterios:

a) Que el cliente reciba y consuma simultáneamente los beneficios proporcionados por la ejecución de la entidad a medida que esta la lleve a cabo (ver párrafos B3 y B4 de la NIIF 15).

b) Que la ejecución de la entidad cree o mejore un activo (por ejemplo, trabajos en curso) que el cliente controle a medida que el activo se cree o mejore (ver párrafo B5 de la NIIF 15).

c) Que la ejecución de la entidad no cree un activo con un uso alternativo para ella (ver párrafo 36 de la NIIF 15) y la entidad tenga un derecho exigible al pago de lo ejecutado hasta la fecha (ver párrafo 37 de la NIIF 15).

\section{LA NUEVA NORMA DE ARRENDAMIENTOS (NIIF 16)}

\subsection{Reforma de la contabilidad de los arrendamientos}

Para numerosas empresas la NIIF 16 será, de las tres normas analizadas, la que mayor impacto conllevará en sus estados financieros. En los últimos años, se han llevado a cabo numerosos análisis con el objetivo de estimar la magnitud de los cambios esperados en las cifras contables y en las métricas de las empresas una vez que la NIIF 16 se implemente (ver Morales y Zamora 2018). Dichos análisis demuestran importantes impactos en ratios de apalancamiento, ROA o EBITDA en sectores como retail, hoteles, compañías aéreas, etc. debido a que son sectores que mantienen gran volumen relativo de arrendamientos que actualmente se consideran operativos.

La reforma de las normas contables que regulan los arrendamientos (esto es, la reforma del modelo incluido en la NIC 17) ha estado en discusión durante varias décadas. Tan pronto como en el año 1996 varios emisores de normas (G4+1, incluyendo el antiguo IASC y el FASB) propusieron un cambio de modelo que ya preveía la capitalización de los arrendamientos operativos (McGregor 1996). El proceso de reforma se aceleró cuando la $\mathrm{SEC}^{30}$ recomendó que se reconsiderara el modelo contable aplicable a los arrendamientos (SEC 2005).

Durante las reuniones del IASB en marzo y abril de 2006, se barajó la posibilidad de incorporar la contabilidad de arrendamientos en la agenda. Desde entonces, el IASB y el FASB comenzaron a trabajar en el nuevo modelo (proyecto conjunto de contabilidad de arrendamientos).

A lo largo del proyecto los organismos concluyeron (en línea con lo que se había concluido en estudios anteriores) que, a pesar de que se puede argumentar que en una operación de arrendamiento el arrendatario obtiene un activo (el derecho de uso del bien arrendado) y un pasivo (la obligación de pago de las

${ }^{30}$ Securities and Exchange Commission. 
rentas futuras), dicho activo y pasivo no se reconocen en el balance en numerosas ocasiones (concretamente en los casos en los que el arrendamiento es clasificado como operativo). Por tanto, comenzaron a desarrollar un modelo en el que la mayor parte de arrendamientos se reconocieran en balance por parte de arrendatario.

Para Duke et al. (2009) las compañías habían disfrutado de los beneficios de los arrendamientos operativos durante décadas debido a que tanto los activos arrendados como los pasivos podían mantenerse fuera de balance solamente con notas de desglose con relación a los futuros pagos de arrendamiento.

La primera propuesta del nuevo modelo (el primer borrador de norma) se emitió por parte del IASB en 2010. Posteriormente se emitió un borrador revisado en 2013. La norma definitiva (la NIIF 16) se emitió en enero de 2016. En el ámbito de USGAAP el ASC Topic 842 se emitió en febrero de 2016.

El desarrollo del nuevo modelo no estuvo exento de críticas. Numerosas empresas e instituciones cuestionaron la capitalización de los arrendamientos operativos debido, sobre todo, al incremento en el apalancamiento y a los costes de implementación de la nueva norma (ver Fitó, et al. 2013). Argumentaron que no se puede igualar una deuda financiera a un arrendamiento en el que en numerosas ocasiones es posible rescindir el contrato sin penalización o con una penalización baja.

Tal y como señala Expansión (2016): "Santander, BBVA, Inditex, Telefónica, Iberia, Repsol, NH Hoteles e incluso El Corte Inglés se unieron en 2010 para detener el plan del IASB de forzar un aumento de su deuda al incluir el coste de los contratos de alquiler en los balances. En sus alegaciones, llegaron a contar con el apoyo del Ministerio de Economía e incluso, parcialmente, de la Comisión Europea. En esos momentos de grave crisis financiera, las empresas pensaban que un aumento de su pasivo podía generarles descensos de rating, aumento de costes y huida de inversores".

No obstante, el IASB y el FASB consideraron que los beneficios que el nuevo modelo conllevaría con relación a la información que se ofrece a inversiones y usuarios de información financiera compensarían los costes. De hecho, aproximadamente la mitad de la cartas de respuesta recibidas a los borradores apoyaban el proyecto basándose en el argumento del incremento de la calidad de la información financiera (Fitó et al., 2013)

\subsection{El nuevo modelo contable para los arrendatarios}

El principal cambio de la NIIF 16 se centra en el modelo aplicable por parte de los arrendatarios (el modelo aplicable por parte de los arrendadores no se ve modificado prácticamente). 
Bajo NIC 17, los arrendatarios (al igual que los arrendadores) debían clasificar todos los contratos de arrendamiento en dos categorías: arrendamiento operativo o arrendamiento financiero (ver párrafo 7 a 19 de la NIC 17). La clasificación dependía de si los riesgos y beneficios inherentes a la propiedad del activo se traspasaban del arrendador al arrendatario.

En los arrendamientos operativos el arrendatario simplemente reconocía un gasto por arrendamiento (en este caso, los riesgos y beneficios inherentes a la propiedad del activo no se traspasan). En cambio, en los arrendamientos financieros el arrendatario reconocía la operación básicamente como una compra financiada del bien (reconociendo el bien en el activo y una deuda en el pasivo).

Bajo NIIF 16 desaparece la distinción anterior para los arrendatarios y todos los arrendamientos se contabilizan siguiendo el mismo modelo (con alguna excepción), el cual suele denominarse "modelo de capitalización" (similar al antiguo modelo de arrendamientos financieros).

El modelo se basa en reconocer en balance un activo (el derecho de uso del bien arrendado) y un pasivo (relacionado con las cuotas futuras a pagar). El pasivo se reconoce inicialmente como el valor actual de las cuotas futuras a pagar durante el período de arrendamiento y el activo se reconoce inicialmente por un importe igual al pasivo más otros conceptos tales como pagos realizado antes del día de inicio o el día de inicio (menos incentivos), costes directos iniciales, estimación de costes de desmantelamiento o retiro del activo, etc. (ver párrafos 22 a 28 de la NIIF 16).

A partir del reconocimiento inicial:

- El activo se amortiza durante la vida del arrendamiento siguiendo lo establecido en la NIC 16 (generalmente de forma lineal) y se estima el correspondiente deterioro de valor (ver párrafos 29 a 33 de la NIIF 16). En algunos casos podría valorarse a valor razonable (ver párrafos 34 y 35 de la NIIF 16).

- El pasivo se valora como un préstamo. Esto es, se incrementa por el devengo de intereses y se reduce por el pago de las cuotas (ver párrafos 36 a 38 de la NIIF 16). Cabe destacar que si las cuotas a pagar son en moneda extranjera el pasivo generaría diferencias de cambio ${ }^{31}$.

- En caso de modificación de los pagos futuros del arrendamiento (y asumiendo que no se trata de un nuevo arrendamiento), la diferencia entre el valor actual de los nuevos pagos futuros y el pasivo en balance antes de la modificación se reconoce contra el activo (a no ser que éste se quede a cero en cuyo caso cualquier reducción adicional se llevaría contra la cuenta de

${ }^{31}$ De hecho, la NIIF 16 modifica el párrafo 16 de la NIC 21 para aclarar que el pasivo por arrendamiento es un pasivo monetario. 
resultados). Si se utiliza el tipo de descuento original o un nuevo tipo depende de la naturaleza del cambio en los flujos. Por ejemplo, si es por una referencia al índice de precios se utiliza el tipo de descuento original, si es por un cambio en el plazo estimado se utiliza un nuevo tipo de descuento (ver párrafos 39 a 46 de la NIIF 16).

La norma prevé algunas excepciones voluntarias en el modelo de capitalización: arrendamientos de corto plazo (menos de un año), arrendamiento de bienes de bajo importe (valor del bien nuevo inferior a unos 5.000 dólares estadounidenses) y arrendamiento de bienes intangibles. En estos casos, si se aplica la excepción, la cuota de arrendamiento simplemente se reconocería como gasto (al igual que los antiguos arrendamientos operativos).

Por otro lado cabe destacar que la NIIF 16 incluye algunas elecciones de política contable o estimaciones que pueden influir significativamente en el impacto de su implementación. Por ejemplo:

- Separación de componentes. En el caso de que un contrato de arrendamiento incluya pagos por componentes que no son arrendamiento (por ejemplo, servicios o suministros) en principio dichos pagos deben excluirse del modelo de capitalización (NIIF 16 párrafo 12). No obstante, como solución práctica, los arrendatarios pueden elegir (por tipo de activo) incluir la renta completa como si toda se refiriera a arrendamiento (NIIF 16 párrafo 15).

- Exclusiones del modelo de capitalización (mencionadas más arriba) (ver párrafos 4, 5 y 6 de la NIIF 16).

- Opciones de primera aplicación. La norma da dos posibles opciones: retrospectiva total y retrospectiva modificada (esta última con dos variantes). En la retrospectiva total deben rehacerse los estados comparativos pero en la retrospectiva modificada no.

- Tipo de descuento. En principio, a la hora de descontar los flujos de arrendamiento, debe utilizarse el tipo implícito del arrendamiento. No obstante, si éste no está disponible, puede utilizarse el tipo de interés incremental de deuda del arrendatario (ver NIIF 16 párrafo 26).

- Plazo del arrendamiento / opciones de compra. En caso de que existan opciones de ampliación, cancelación anticipada u opción de compra a favor del arrendatario debe estimarse si es "razonablemente cierto" su ejercicio (ver NIIF 16 párrafos 18 y 27).

\section{CONCLUSIONES}

Las nuevas normas contables (NIIF 9, NIIF 15 y NIIF 16) supondrán importantes impactos en los estados financieros de las empresas. Dependiendo de las actividades de la empresa (los contratos con clientes), los instrumentos 
financieros que mantenga o los tipos de arrendamiento que firme, los impactos pueden ser mayores o menores.

En algunos casos, los estados financieros pueden cambiar en gran medida debido a la capitalización de los antiguos arrendamientos operativos siguiendo la NIIF 16. En este sentido, por ejemplo, una empresa que no tuviera un gran volumen de deuda (apalancamiento) puede ver que dicho volumen se incremente de forma significativa.

En cualquier caso se recomienda a las empresas que analicen los impactos de las tres normas desde varios puntos de vista:

- Impactos en políticas contables. Esto es, cambio en la forma de contabilización de las operaciones y adaptación de las políticas contables internas a las nuevas normas. En este ámbito, las empresas deberán tomar varias decisiones relacionadas con las nuevas normas, ya sea de elecciones de tratamiento contable (cuando las normas permitan varias alternativas) o de estimaciones.

- Impacto en los sistemas. Los sistemas contables tendrán que adaptarse a las nuevas normas. Con relación a la NIIF 16 numerosas empresas están actualmente implementando nuevos sistemas que sean capaces de contabilizar los arrendamientos bajo la nueva normativa. Ocurre algo similar, por ejemplo, con las nuevas provisiones por riesgo de crédito bajo NIIF 9 o los nuevos ingresos de contratos con clientes bajo la NIIF 15.

- Impacto en los procesos de negocio. Las nuevas normas pueden conllevar cambios en varios procesos de negocio. Por ejemplo, una vez implementada la NIIF 16, a la hora de contratar un nuevo arrendamiento se establecerá un procedimiento que conllevará su análisis contable preliminar, alta en el sistema, nivel de aprobaciones, etc. En otro ejemplo, una vez implementada la NIIF 9, a la hora de adquirir un activo financiero se establecerá un nuevo procedimiento relacionado con los test de modelo de negocio y flujos contractuales.

- Otros impactos. Las nuevas normas pueden tener impacto el cualquier aspecto que tome las cifras contables como base, desde covenants de deuda hasta remuneraciones a empleados.

\section{REFERENCIAS BIBLIOGRÁFICAS}

DUKE, J.C., HSIEH, S.J., y SU, Y, (2009). "Operating and synthetic leases: Exploiting financial benefits in the post-Enron era". Advances in Accounting, incorporating Advances in International Accounting, 25, pp. 28-39 
EXPANSIÓN (2016). "Una nueva norma contable subirá la deuda del Ibex en 40.000 millones". Expansión 13/01/2016. Disponible en: https://www.economistas.es/ contenido/consejo/ResumenPrensa/2016/Enero/13/1-contab.pdf

EXPANSIÓN (2018). "Telefónica, Iberdrola y Repsol afrontan ajustes millonarios en sus costes en 2018". Expansión 27/01/2018. Disponible en: http://www.expansion.com/ empresas/2018/01/27/5a6b892ae5fdea3b1d8b45a1.html

EY (2012). "International GAAP 2012". John Wiley \& Sons. Chichester, West Sussex (Reino Unido).

EY (2017). "IFRS Developments. IASB issues an Amendment to IFRS 9". Disponible en: http://www.ey.com/Publication/vwLUAssets/ey-devel130-fi-amendmentoct2017/\$FILE/ey-devel130-fi-amendment-oct2017.pdf

EY (2018). "International GAAP 2018". John Wiley \& Sons. Chichester, West Sussex (Reino Unido).

FITÓ, M.A., MOYA, S., y ORGAZ, N. (2013). "Considering the Effects of Operating Lease Capitalization on Key Financial Ratios". Revista Española de Financiación y Contabilidad, 42 (159), pp.341-69.

GEORGIOU, O. y JACK, L. (2011). "In Pursuit of Legitimacy: A History Behind Fair Value Accounting". The British Accounting Review, 43, pp. 311-323.

IASB (2008), "Discussion Paper: Reducing Complexity in Reporting Financial Instruments". Disponible en: https://www.asc.gov.sg/Portals/O/attachments/ Consultations/dp-\%20reducing\%20complexity\%20in\%20reporting\%20financial\% 20instruments.pdf

MCGREGOR, W. (1996). "Financial Accounting Series. Special Report. Accounting for Leases: A New Approach". FASB. Norwalk, CT (EEUU).

MORALES-DÍAZ, J. (2012). "La Problemática Contable de los Contratos de Factoring". Partida Doble, 239, pp.10-29.

MORALES-DÍAZ, J. (2014). "Tratamiento contable de las operaciones de reestructuración de deudas bajo NIIF". Revista Contable, 18, pp.40-54.

MORALES-DÍAZ, J. y ZAMORA-RAMÍREZ, C. (2018). "The Impact of IFRS 16 on Key Financial Ratios: A New Methodological Approach". Accounting in Europe, 15(1), pp.1-33.

SEC (2005). "Report and Recommendations Pursuant to Section 401(c) of the Sarbanes-Oxley Act of 2002 On Arrangements with Off-Balance Sheet Implications, Special Purpose Entities, and Transparency of Filings by Issuers". Disponible en: http://www.sec.gov/news/studies/soxoffbalancerpt.pdf. 